\title{
Descriptive Study of Roofless People in the Post Soviet Georgia
}

\author{
Shorena Sadzaglishvili ${ }^{1, *}$, Stuart Scharf ${ }^{2} \&$ Tinatin Kalandadze $^{1}$ \\ ${ }^{1}$ Ilia State University, 3-5 Cholokashvili Street, 0162 Tbilisi, Georgia, USA \\ ${ }^{2}$ Mid-Hudson Forensic Psychiatric Center, New Hampton, NY 10958-0158, USA \\ *Corresponding author: Ilia State University, 3-5 Cholokashvili Street, 0162 Tbilisi, Georgia, \\ USA. Tel: 1-995-577-501-577. E-mail: shorena_sadzaglishvili@iliauni.edu.ge; \\ ss2051@columbia.edu
}

Received: November 24, 2017 Accepted: December 6, 2017 Published: December 15, 2017

doi:10.5296/jsr.v9i1.12179 URL: https://doi.org/10.5296/jsr.v9i1.12179

\begin{abstract}
Homelessness is a complex problem, resulting from a combination of housing and social exclusion processes. This paper discusses the major factors contributing to homelessness in the post soviet Georgia. Though there is no consensus on understanding conceptual typology, the causes and complexity of homelessness, there are currently three categories of homeless people identified as "homeless" in Georgia. Among them so called "Roofless" people are the most vulnerable groups who need special attention while there is no national strategy on homelessness in place.
\end{abstract}

Mixed methods were used to study homeless people living in a special shelter in Tbilisi. In total, 70 homeless (Mean Age $=48$, Male $-64 \%$, Female $-36 \%$ ) were interviewed by semi-structural questionnaire.

The results showed that a structural factor - unemployment $(90 \%)$ is the major cause of homelessness. The other factors include: lack of support system (69\%), relationship problems or family breakdown $(66 \%)$, health problems $(64 \%)$, mental problems $(44 \%)$, internal migration (39\%), leaving prison $(26 \%)$, substance abuse $(16 \%)$. The profile of homeless persons in Georgia is a middle-aged single man; however, the numbers of homeless women, elderly and younger people as well as families with children are growing.

Furthermore the paper suggests that understanding the local contexts of poverty can assist government for building the proper national strategy on homelessness and facilitate social inclusion of the most disadvantaged groups of people.

Keywords: Homelessness, Rooflessness, Poverty, Unemployment, Post communist country, Social Exclusion/Inclusion 


\section{Introduction}

Homelessness is a complex problem, resulting from a combination of housing and social exclusion processes (Edgar, 2012). Homelessness problem is very new for the post-soviet countries having the history of the private housing policy which resulted in providing many soviet families with their own "separate apartments" by the Government (Attwood, 2010). Moreover, since unemployment was rendered unviable through various acts of legislation, "the Soviet worker", in contrast to "a Capitalist worker", was more secured economically (Arnott, 1988). It was required to hire worker if she/he was directed by welfare authorities and also, there were plentiful jobs available (Madison, 1968). In addition, the Soviet wage system tried systematically to make wages more equal (Arnott, 1988).

After the collapse of Soviet Union, Georgia moved from having a tradition of "no social problems" towards facing major social and economic challenges (IFSW, 2014). In fact, Georgia has one of the highest inequity and poverty levels in Europe. Substantial part of the adults and child population is still living below the poverty line. Poverty, limited employment opportunities, income disparity, and social exclusion of the most vulnerable create challenges for developing country. The official unemployment rate of 15.1 percent in 2011 (GEOSTAT, 2011) masks the real situation considering the fact that 64 percent of the employed are self-employed, of which a large share is engaged in subsistence farming. Access to education and health services are constrained by physical barriers, societal attitudes, and financial issues (UNDP, 2013). The Government of Georgia implements socially oriented agenda to address poverty and social vulnerability. The current priorities of the state social protection system include eradication of extreme poverty, social exclusion and improving living standards of the most vulnerable. Only in 2013 the budget of the Ministry of Labor, Health and Social Affaires increased by $28 \%$ compared to the previous year.

Among the most disadvantaged groups of people who have limited access to assets and basic services are internally displaced people (IDP) who are the victims of the internal conflicts in the 1990s in South Ossetia and Abkhazia and the 2008 Georgian-Russian war. Georgia currently counts 258,595 IDPs out of a total population of 4.5 million. The most pressing issues among IDPs are inadequate housing conditions and high levels of unemployment (UNDP, 2013). The Government of Georgia (GoG) has set up a range of public policies targeted towards IDPs. Registered IDPs are entitled to a monthly allowance as well as durable housing solutions programs. For instance, from 2013, within the program assuring IDPs long-term accommodation, accommodations are granted to IDPs on the initiative of the Ministry and local and international non-governmental organizations in accordance with established criteria and procedures (Order N320 09.08.2013 of Minister of Internally Displaced Persons from the Occupied Territories). Consequently, from August 2013 until now, 13041 IDP families, across the country, have submitted the application to the Ministry to get an accommodation and long-term accommodation has been provided to 1353 IDP families (Minister of Internally Displaced Persons from the Occupied Territories, 2016).

Besides IDPs there are other social vulnerable groups who have lost their housing or are under the risk to lose house due to the lack of financial, human (education, labor, health) and 
social resources (UNDP, 2013); In contrast to IDPs, socially vulnerable people are entitled only to very limited options, e.g. temporary/24 hour shelter in Tbilisi and 20 social houses in 7 cities (for IDPs as well as socially vulnerable people). There is a need to develop an action plan and housing strategy under the National Strategy for the Protection of Human Rights (2014 - 2020), which will include estimation of the necessary financial means for addressing the housing problem of homeless persons and gradually mobilize them in the state Budget (Public Defender of Georgia, 2015). Thus, homelessness becomes one of the major critical social problems in Georgia. There are no accurate databases of homeless persons caused by the vagueness of the definition of homeless person and absence of methodology for determining the status of homeless.

Finally, there are three visible groups that can be identified as homeless people. (1) Families who applied to the self-government unit requesting shelter. For instance, according to the data provided by the Municipalities of different cities of Georgia there are about 13,554 citizens who addressed the self-government units with a request to receive housing. (2) Roofless people, the most vulnerable groups, who live in streets and in temporary shelters. There are 180 persons in Tbilisi shelter. And (3) Homeless people who are willfully settled in the state and private buildings (about 6,319 families) and social housing (500 families). These people are mostly internally displaced persons (51\%), ecological migrants and other status $(21 \%)$ and socially disadvantaged people (28\%).

This paper discusses some research done in western countries regarding the understanding homelessness itself and the dynamics of homelessness. In addition, this article will present local research findings on homelessness and highlight the major factors contributing to homelessness (in particular, rooflessness) as well as possible recommendations for alleviating homelessness and developing strategy for social inclusion of the most disadvantaged groups of people in Georgia.

\section{Understanding the Dynamics of Homelessness: Western Experience}

There is no consensus on an international level over the definition of homelessness. The definition varies from those being quite narrow according to which homelessness is the 'absence of a roof above one's head' to a broader one according to which homelessness depends on the quality of accommodation, probability of homelessness, its duration and the responsibility for a response (UN, 2011). The difficulties of defining homelessness impact on the ability of governments to adequately and appropriately respond to homelessness.

The conceptual definition of homelessness proposed by FEANTSA (The European Federation of National Organizations Working with the Homeless), which is known by the acronym ETHOS (European Typology of Homelessness and Housing Exclusion) aims to conceptualize a consensual definition of homelessness (and housing exclusion) across the EU (FEANTSA, 2010). ETHOS defines homelessness in reference to three "domains", which are defined as constituting a 'home', the absence of which can be taken to delineate homelessness. Having a home can be understood as: having a decent dwelling (or space) 
adequate to meet the needs of the person and his/her family (physical domain); being able to maintain privacy and enjoy social relations (social domain) and having exclusive possession, security of occupation and legal title (legal domain). Different forms of homelessness are identified according to their relation to the three domains of homelessness. There are four main conceptual categories for definition of Homeless and Housing Exclusion. These types vary between rough sleeping on the one side and living within a decent and legally occupied dwelling without safety (e.g. women who experience domestic abuse) on the other side (FEANTSA, 2010).

One of the categories is so called "Roofless" people who have no living space of their own over which they have any control. They are excluded from the social domain because they have no private space. In addition, they are excluded from the legal domain, because they have no legal title and no security of tenure to any form of housing or accommodation (FEANTSA, 2010).

Many developing countries have chosen "roofless people" as on the most extreme forms of homelessness including the most destitute persons (rough sleepers and persons in emergency accommodation). It automatically leads to a smaller size and higher proportion of persons with serious support needs and burdened life histories than if a broader definition is applied including the "houseless" and different household types (including families) in temporary accommodation.

In our study, we will use the most obvious definition of homelessness which is 'street homelessness' or 'rooflessness', terms used to refer to those who are without shelter of any kind. This constitutes the narrowest definition of homelessness. It should be noticed that rough sleeping represents the experience of only a minority of homeless persons and cannot be expand to other groups of homeless people in general (Pleace, 2000).

According to Edgar (2009) there are four broad risk factors increasing the probability homelessness. These are structural factors (such as economic processes causing poverty and unemployment, housing market processes, welfare/ social protection system and immigration and citizenship issues), institutional factors (shortage of adequate mainstream services and lack of co-ordination between existing services to meet demand or care needs, institutional living (Foster/Child Care), prison, long-term hospital, institutional procedures (admission, discharge) and etc.), relationship (family status, relationship situation (abusive partners or parents), relationship breakdown) and personal factors (disability, long-term illness/mental health problems, low educational attainment, and addiction). In addition, triggers refer to specific events which may lead directly to an episode of homelessness, or to a further step in a 'career', which may ultimately result in homelessness.

According to O'Flaherty (2004), homeless entries are often not the result of a single event or trigger, rather than it is "a conjunction of unfortunate circumstances". In other words, a confluence of adverse individual and structural events can most likely to trigger homelessness. "New orthodoxy" or "new interpretation" of the causes of homelessness hypothesizes that structural factors create the conditions within which homelessness will occur; and people with personal problems are more vulnerable to these adverse social and economic trends than 
others; therefore the high concentration of people with personal problems in the homeless population can be explained by their susceptibility to macro-structural forces (Fitzpatrick et al., 2009). Homelessness is a process leading to vulnerability in the housing market, which may result in housing exclusion or visible homelessness. In addition, homeless people are not passive victims of forces beyond their control, rather than they are human agents who accumulate human, social, material, and financial capital which enable them to overcome the negative effects of structural factors (McNaughton, 2008; Cloke et al. 2010).

It has been hypothesized that countries with less favorable social and economic conditions will have a higher overall prevalence of homelessness, but a low proportion of their relatively small homeless populations will have complex personal problems (Fitzpatrick, 1998). The reverse would be true in countries with well functioning housing and labor markets and social security policies (low prevalence of homeless, but high proportion of complex personal problems).

Important differences in typical pathways into homelessness can be found according to age and gender. The majority of homeless persons in most European countries are still being single and middle-aged men (Fitzpatrick and Stephens, 2007; Stephens et al., 2010) and having immigration status. Especially, in many EU countries (especially among the EU-15) there are a growing proportion of immigrants among the street homeless and among homeless service users (in some countries this is the majority). However, the profile of homeless people is changing and there are a growing proportion of women, younger people and families with children. Furthermore, while most homeless people have low educational attainment and are unemployed, there are a growing proportion of people with higher levels of education and who have part-time and low-paid employment (Frazer et al., 2010).

While relationship factors represent key variables in the description of homelessness among women - and domestic violence in particular (Edgar and Doherty, 2001) - they are not a sufficient explanation of women's pathways into homelessness. The most relevant factors are increased risk of poverty for women and the consequences of changes in household composition (more female-headed households, more single mothers, increased participation in the low-paid segments of the labor market). For example, data in a number of countries show a high rate of rent arrears and evictions as triggers for homelessness among women. Also, there are indications that homeless women are often younger than homeless men and there is a higher share of homeless women with a migration background (Edgar and Doherty, 2001).

Research showed that 16 and 17-year-old young people accepted as homeless were an extremely vulnerable group, who had often experienced educational and/or family disruption and mental health and/or substance misuse problems (Pleace et al., 2008). In contrast, a large study in the UK has shown that families accepted as homeless under the national homelessness legislation, while being a disadvantaged group with respect to their health and access to social support (and experience of domestic violence), were not a vulnerable group, with very few self-reported current drug or alcohol problems. In addition, despite women's experience of negative discrimination in many fields, the lower proportion of women among 
homeless persons and the fact that they often experience shorter periods of homelessness than men point to the effects of positive discrimination such as priority for women, and especially for women with children, in the allocation of housing and in the provision of social support, and also to greater support from family and friends (Marpsat, 2008).

The other classification of homeless entries and 'causes' of homelessness across different countries distinguishes between those leading only to a relatively short and singular episode of homelessness (transitional homelessness), those involving several episodes of homelessness (episodic homelessness) and those where homelessness has been experienced without interruptions for years (chronic homelessness; May, 2000).

A survey of 3,630 households imminently threatened with homelessness and in contact with one of forty-three municipal homelessness prevention services across Germany showed that 40 per cent of these households were judged by workers within the prevention services to be in need of more specialized support with addiction, mental health problems or other social difficulties. The remaining 60 per cent needed only short-term crisis intervention and financial support as a great majority of all households being under threat of eviction (Busch-Geertsema et al., 2005). This research showed that long-term homeless people constitute a minority of service provider clients in Germany.

Culhane and Kuhn (1998) showed that homeless people in two major cities in the United States fell into two main categories. The largest, transitionally homeless group was made up of people who experienced homelessness linked to relationship breakdowns and poverty, and who did not generally stay homeless for very long. This transitionally homeless group existed alongside a smaller group of chronically homeless people with high rates of severe mental illness or drug and alcohol use, with high support needs who were living rough and/or in emergency shelters either repeatedly or on a permanent basis.

To summarize, homeless persons are not purely passive victims of 'objective' forces at work, but often have to choose between very restricted options under difficult circumstances (McNaughton, 2008). It is a very complex task to comment on homeless entries and 'causes' of homelessness across different countries due to (1) homeless numbers are still extremely difficult to compare across countries (Edgar, 2009; Stephens et al., 2010) and (2) different national conceptions of homelessness can have the reverse effect; for example, a restricted definition of homelessness is more common in those countries with less well-developed structural conditions and broader definitions are more established in countries with favorable structural conditions.

\section{Study Purpose and Methods}

The purpose of this study was to understand the pathways to homelessness among the most vulnerable group of roofless people in Tbilisi, capital of Georgia.

Mixed methods were used to study roofless people living in a special shelter in Tbilisi. In total, 70 homeless(Note 1.) (Mean Age $=48$, Male - 64\%, Female - 36\%) were interviewed 
by a trained interviewer using a semi-structural questionnaire including 92 close and open ended questions regarding demographics, pathways to homelessness, substance abuse, health and mental status, social competence and other issues. Substance abuse questions were adopted from Tarter and Hegedu's "The Drug Use Screening Inventory" (1991). Answers on open-ended questions were content-analyzed.

Respondents were selected by purposive sampling, with use of "snowballing", signed informed consents and were informed about all risks and benefits of participation, right to refuse participation with no penalty or interruption of services, and the protection of anonymity and confidentiality. The interviews took place in May 2015, Tbilisi.

\section{Results}

\subsection{Structural Factors}

The overwhelming majority of our respondents were unemployed or occupied very low-skilled and unstable jobs and moved to big cities to find jobs. These common risk factors contributed to homeless entries for almost all persons who became roofless in Georgia.

In our study, the results showed that structural factors were dominant in defining homelessness. In particular, $90 \%$ of all interviewed respondents were unemployed, 39\% of all interviewed respondents moved to the capital city - Tbilisi for job search (so called internal migration), $66 \%$ of all interviewed respondents were registered in Tbilisi and $7 \%$ did not have identification cards at all. It should be mentioned that $20 \%$ of roofless people had their ancestry country houses in the region. However, majority of the respondents refused to go to region (90\%) even if the government provided adequate assistance to them because lack of services and employment opportunities in the regions. Moreover, almost half of the respondents mentioned (52\%) that they were not making any efforts to find jobs. The major reasons of their inactivity as named by them were: health problems, disability, frustration, depression, social exclusion and nepotism. Interviewed respondents lived on an average 65 GEL - \$27 (Min 0 and Max. 650 GEL - \$230) per month. It included salary as well as governmental assistance -pension, disability allowance, IDP assistance, and etc. App. 56\% of all interviewed respondents' did not have any allowance. $3 \%$ of all interviewed homeless respondents were internally displaced people (IDPs), $16 \%$ received disability allowance, 11\% - old age benefits- pension and app. 3\% - subsistence allowance, and $7 \%$ had temporary jobs. Only $3 \%$ of all respondents were employed on a regular basis but on low-paid jobs. $41 \%$ of respondents needed assistance in finding jobs and $21 \%$ were ready to attend professional trainings to improve their employability skills.

Thus, the major triggers for most of the respondents were structural factors. Roofless people in Georgia were migrated form the regions, changed their status and were not able to find jobs and pay for housing. This situation is worsened by the nonexistence of affordable housing for disadvantaged persons in Georgia. Moreover, there is no prevention policies into play that can contribute greatly to a reduction of homelessness despite growing poverty and unemployment (Busch-Geertsema and Fitzpatrick, 2008). Social protection is another most 
important structural factor not introduced in Georgia so far. In particular, there is no unemployment programs or minimum benefits available to cover reasonable housing costs and the costs of living for low-income habitants. Therefore, the risk of homelessness and housing exclusion is much higher in Georgia due to the structural factors.

\subsection{Relational Factors}

Results showed that relationship problems were one of the most frequently mentioned immediate triggers for homelessness in Georgia. In fact, escalating conflicts in an existing relationship, abusive partners or parents, separations or bereavements were quite common factors leading into homelessness. $69 \%$ of interviewed homeless people mentioned that they did not get any support (physical or emotional) from close relatives even though 91\% mentioned having close relatives (spouse, parents and children). $40 \%$ of interviewed respondents mentioned that they had "cut off" relationship (or relationship breakdown) with their close relatives. $29 \%$ indicated that they had serious family conflicts and $7 \%$ were victims of domestic violence.

Family status of interviewed respondents showed that $50 \%$ were divorced or separated, app. $16 \%$ were widowed and app. $19 \%$ had never married while only about $16 \%$ of all respondents were in registered or nonregistered relationships. $6 \%$ of respondents were eager to get assistance in child support services $(6 \%)$ and improve family household management skills $(9 \%)$.

Our results showed that the proportion of roofless respondents who undergone very difficult experiences earlier in their life course, such as domestic violence, separation, leaving the parental home at an early age or the death of a parent during childhood is significantly higher than among the general population. By bringing in a fuller consideration of participant narratives and expressions, we find some support for above speculations:

"I married early, I did not have enough time to study. In my village, nobody supported me to study. My parents did not want me to study... they would get crazy, If I went to school.... I have no education and can't find any job.. Nobodywants me";

I married early, My husband was abusive and I left him. I could not return to my family-of-origin. I lost everyone, I do not know how to start new life, I am lost",

"I'm divorced with my husband and left home. I tried to divorce my husband earlier but I was afraid. Now I live here, my life is cruel. "

\subsection{Personal Factors}

Personal characteristics influence to a great extent and increase vulnerability to homelessness. In our study, about $16 \%$ of respondents used alcohol 10-20 times (8.57\%) and more than 20 times $(7.14 \%)$ in the last month. Pain killers were used by about $12 \%$ of interviewed respondents more than 20 times during the last month. $14 \%$ indicated that they had serious substance abuse problems. $4 \%$ of interviewed respondents named gambling issues as the 
major reason for becoming homeless.

$64 \%$ of all respondents had serious medical/health problems and $47 \%$ currently took medicine to solve their medical problems. $57 \%$ respondents mentioned that they had less energy than usual. $40 \%$ had casual sexual activities and $14 \%$ could catch sexually transmitted diseases including HIV/AIDS.

The general behavioral patterns of interviewed roofless person in Tbilisi were as follows: a loner (57\%); very sensitive to criticism (54\%); easily upset (50\%); very shy (43\%); a suspicious of other people (24\%); a bad temper (23\%); generally feels angry (23\%); swears or uses dirty language (20\%); takes an advantage of people if he/she can (17\%); and argues a lot $(14 \%)$;

About $44 \%$ of interviewed homeless respondents had more than average level of psychiatric symptoms $(M=5.7 ; S D=3)$. Most of the respondents showed minimal social competences. For instance, they were afraid to stand up for their rights $(66 \%)$; it was very difficult to ask for help from others (50\%); it was difficult to make friends $(26 \%)$; they avoided an aye contact when talking to people (24\%) and easily influenced by other people (17\%).

It is remarkable that $19 \%$ of all interviewed respondents had high academic education, $4 \%$ incomplete high education and $17 \%$ - high professional and technical education. $60 \%$ of respondents needed assistance in health care services, $4 \%$ is were ready to get rehabilitation services to fight addiction, 3\% needed life skill training and $9 \%$ needed assistance in legal issues.

Our results showed that respondents undergone a lot of mental health problems and increased substance misuse that was triggered by personal inability to get adequate support that increased their risk of becoming homeless.

\subsection{Institutional Factors}

Institutional factors - for example, if persons in need do not receive adequate support because services are not available or are not coordinated adequately - can increase vulnerability to homelessness. In our study, $26 \%$ of homeless people were previously in conflict with the law and recently released from the prison and $1 \%$ left the state care institution after becoming 18 years old.

There is no adequate support for children who are at institutional care in Georgia that increases institutional vulnerability for children after 18. In addition, leaving prison is a key trigger for homelessness as a period of incarceration may be a precursor for eviction and relationship breakdown.

\subsection{Profile of Roofless Person in Georgia}

According to our study, the average length of homelessness was 8 years and the most frequent length of homelessness amounted 2 years among the interviewed respondents. Interviewed roofless people spent 11 month on an average (minimum 1 months and maximum 18 months) in the shelter. The profile of homeless persons in Georgia was a 
middle-aged (48 years old) single man (64\%).

Homeless families were very rare $(17 \%)$ in the shelter and their children were placed in the foster care $(13 \%)$ and only $1 \%$ stayed in the shelter. $8.6 \%$ of interviewed respondents were 30 and under 30 years old. The most frequent age was 47 years old. The number of old people 60 and older was $11 \%$. Minimum age was 17 years old and Maximum age was 78 years old.

\section{Discussion and Recommendations}

The study showed that there are multiple factors facilitating the pathways to homelessness in Georgia. However, the most influential are structural factors such as poverty and unemployment caused by the current social economic challenges in the post communist transitional country. Full reliance on market forces and limited role of the government in the housing sector resulted in raising numbers of homeless adults and children living and working on the streets, persons illegally occupying state or private owned property and etc. Impoverished people were urged to sell their apartments or to take real-estate loans from the bank in order to support families economically, save lives of their loved sick and disabled family members, to deal with their traumatic life event (a separation, the death of a partner, lose of the job, and etc.). The extreme poverty in the regions increased internal migration from the regions to the capital city -Tbilisi, which resulted in high numbers of impoverished internal migrants who are unemployed or working in very low-skilled and unstable jobs. Housing needs are obvious among youth leaving from the state childcare institutions, persons with mental health and substance abuse problems, single parent households and families with multiple children living below the poverty line. The risk of homelessness is relatively high among above-mentioned vulnerable groups.

The concept of "Social Protection" which implies to provide assistance to families and children as well as to provide people with basic health and housing in response to various contingencies to offset the absence or substantial reduction of income from work (United Nations, 2000:4) is newly introduced in Georgia and, consequently, there are no effective mechanisms to ensure legal guarantees for the homeless on the legislative level nor unified database of the homeless to keep track on exact statistical data related to the violations of housing rights. Moreover, isolated provisions included in various laws are hardly ever realized in practice (Public Defender of Georgia, 2015). In particular, roofless people have no access to those minimal social benefits designated for the country's poor (in order to get subsistence allowance one should apply to the appropriate territorial unit of Social Service Agency according to the place of residence).

The government of Georgia provides primary state intervention to protect individuals against adverse circumstances through the provision, directly or indirectly, of a range of welfare or social services, which includes childcare services (alternative forms of childcare, early child development programs, rehabilitation of children with disabilities, day centers for socially vulnerable and disabled children, food vouchers, etc.), universal health insurance, old age 
pension, subsistence allowance for poor families, rehabilitation services for people in conflict with the law and etc. At the secondary and tertiary levels there are introduced special programs targeted at the key 'triggers' for homelessness. For instance, there are community homes for disabled and elderly, asylums for mentally ill people, shelters for victims of domestic violence and human trafficking, mobile food services for poor, mobile teams for street connected children, day care/crisis intervention centers for street connected children, 24 hour transition centers for children and adults, shelters for mothers and children, shelters for illegal migrants and etc.

However, Georgia does not have effective legislative system providing legal protection to the homeless persons, nor housing policy provision for homeless (legal right to housing) and adequate targeted services to reduce the population who are currently homeless and/or at risk of homelessness. In particular, preventive services remain underdeveloped in terms of balanced responsiveness towards various target groups, geographic coverage, and quality. There are less affordable housing supply, limited welfare support to meet housing costs, limited access to health and support services, no unemployment benefits, no statutory after-care plans for youth who are leaving public care as well as family support services, and etc.

In the context when adverse structural conditions generate a higher number of households who are actually homeless, the country without any strategy on homelessness, could fail to meet the objectives of the National Strategy for protection of human rights regarding the Right to Adequate Housing. Consequently, there are many different pathways leading into homelessness in Georgia, but limited ways to facilitate social inclusion and sustain exist from homelessness.

There are several recommendations based on our empirical study that can be considered while developing the strategy on homelessness in Georgia.

It is critical to understand and consider how intervening variables such as welfare regimes, housing policy, addiction treatment policy (whether harm reduction or abstinence) and etc., contribute to patterns of homelessness while designing homelessness policy of Georgia. For instance, the provision of housing subsidies targeted on lower income households, such as housing allowances, and the availability of social rented housing can reduce the level of homelessness (Stephens and Fitzpatrick, 2007). Generous welfare regimes are more likely to protect citizens from entering homelessness as a consequence of the range of services that aim to promote social inclusion formally. More generous welfare regimes are also less likely to utilize the criminal justice system, particularly incarceration, as a means of managing marginal households (FEANTSA, 2010). It is also known that the provision of social or non-market-rent housing is a powerful social good, but does not necessarily impact directly on the extent of homelessness. Targeted policies may carry the risk of creating an artificial increase in homelessness. In this context, Georgia should identify its welfare regime/preference and its potential and financial and human resources in regard to develop proper homelessness strategy and homeless service provisions.

There is need to develop operational definition of homeless person in Georgia based on 


\section{Mll Macrothink}

ETHOS definition; define the legal status of homeless persons, which will clearly specify the group of persons covered under the given definition. However, one of the priorities should be to develop and extend effective social services and interventions for the most vulnerable people - roofless who are without shelter of any kind and are in emergency and/or temporary shelters.

Majority of our respondents indicated health problems (64\%) and highlighted (60\%) that they need assistance in health care services in the context where there is universal health care services available in the country. It is obvious that they are stigmatized and encounter difficult attitudes when seeking health care. Stigmatization can block access to health services (Anderson et al., 2005) and it also may form barriers to employment, for example because people living rough are assumed to be involved in problematic drug use (FEANTSA, 2007). However, in our study only $14 \%$ had serious drug addiction. In addition, supported housing providers may be reluctant to engage with people with experience of living rough and to avoid "negative neighborhood effects" (Busch-Geertsema, 2007). Thus, there is a need to work on reducing stigmatization of rough sleepers through their inclusion into the mainstream society by providing individually tailored services. In addition, policy makes should take caution by labeling roofless people as there may be serious consequences arising from being labeled as a person (or household) who is living rough.

It is important to implement an effective legislative system providing legal protection to the clearly defined homeless persons. Besides, it is critical to define the responsibilities of central and local governments on legal level and specify their scope, as well as identify the mechanisms, procedures and timeframe for coordination (Public Defender of Georgia, 2015). In addition, there is a need to cooperate with the non-governmental sector, international organizations, private sector and all stakeholders including beneficiaries to develop effective interventions and diverse services to reduce homelessness in the country.

User involvement in the development of services for homeless people is underdeveloped in Georgia. It is important to provide further participatory, community based research to empower beneficiaries and reveal their views and attitudes on homelessness problem and possible solutions. In our study respondents prefer 24-hour temporary shelter - it provides food and individualized services for beneficiaries for 18 months, sharing space, non-isolated rooms $(36 \%)$, transitional family temporary accommodation - family support/strengthening services, child care services and isolated rooms for families for 3-5 years (33\%) and long term social housing with minimal services and co-payment or minimal rent $(20 \%)$. It is obvious that roofless persons are very disempowered and unable to make better choices. The general behavioral patterns of interviewed roofless people showed that they have very reserved personalities and they need empowerment and assistance in confidence building.

Developing various prevention mechanisms of homelessness should become priority for Georgia. For instance, in a number of countries specialized prevention centers for households threatened by eviction have been implemented during recent decades, which offer proactive support for households, especially with rent arrears. In addition, prevention efforts have often been targeted at mediating domestic conflicts and organizing access to regular housing for 
people leaving institutions (FEANTSA, 2010).

It has high importance to minimize the length of rough sleeping among homeless in the country. Our study showed that the most frequent length of homelessness amounts 2 years among the interviewed respondents. Thus, they are not yet chronically homeless people with multiple support needs rather than they are transitional (people who use emergency accommodation for brief periods of time and do not return) homeless people. However, they may become chronic homeless in case of no effective response from the government to facilitate and sustain exits from homelessness. The extent of poor physical health among people living rough is well documented (Connelly and Crown, 1994; Van Laere et al., 2009; Wright and Tompkins, 2005; FEANTSA, 2006). The dangers to health include exposure to the elements, restricted access to good nutrition and a greater risk of being a victim of violent crime. In general, chronic homelessness is related with high rates of problematic drug and/or alcohol use and severe mental illness.

Our study showed that the numbers of homeless women, elderly and younger people as well as families with children are growing. Consequently, service and policy responses must account for these gender and age differences. It is necessary to provide safe living environments for women and children, that protect them from violence and facilitate access to care, counseling and support services to help them overcome the effects of homelessness. In addition, significant proportions of homeless people are older (over 60 years). There is a need to understand the causes and pathways into homelessness among older and young people. Possible reasons may include lack of community homes for elderly and nonexistence of services for youth leaving state care.

'Housing First' or housing led services has been widely adopted in many countries. This model is considered to be more effective than staircase services (Tsemberis et al., 2004). They are superior as they place people with severe mental illness and problematic substance misuse who are chronically homeless, or at risk of chronic homelessness, in ordinary private rented housing and provide floating support to help them sustain independent living. However, poor joint working with different service providers may limit the effectiveness of such housing-led services. This experience should be incorporated while building homeless services in Georgia. At this stage, Georgia's Government is focused on development of 24 hour temporary shelters and on staircase services rather than on developing on "Housing First' model or housing led services.

Finally, further in-depth qualitative study is needed to grasp the main features of all type of homeless persons in Georgia.

\section{Conclusion}

This study intended to describe only the most disadvantaged members of the society such as roofless people. It is obvious from the study of the roofless people in Georgia, that social structures are critical factors in the causation of homelessness/rooflessness. In particular, the role of structural factors such as the housing market, the lack of affordability of rental 
housing, unemployment, and etc. are more influential than individualist explanations. It is revealed that almost half of the beneficiaries of emergency shelters are unemployed and need assistance in finding jobs even though they have high academic or professional education. In contrast to European roofless people who have multiple and serious support needs and problems (mental health, drag addiction, chronic homelessness and etc.), majority of interviewed roofless people in Georgia are with less burdened life stories and can be more easily rehabilitated in case of timely intervention and accommodation.

\section{References}

Anderson, I., Baptista, I., Wolf, J., Edgar, B., Benjaminsen, L., Sapounakis, A., \& Schoibl, H. (2005). The Changing Role of Service Provision: Barriers of Access to Health Services for Homeless People. Brussels: FEANTSA.

Arnot, B. (1988) Controlling Soviet labor: Experimental Change from Brezhnev to Gorbachev. M.E. Sharpe, Inc. https://doi.org/10.1007/978-1-349-09231-4

Attwood, L. (2010) Gender and Housing in Soviet Russia: Private Life in a Public Space. Manchester: Manchester University Press. https://doi.org/10.7228/manchester/9780719081453.001.0001

Busch-Geertsema, V. (2005). Homelessness and the Changing Role of the State in Germany. Bremen and Brussels: FEANTSA.

Busch-Geertsema, V. (2007). Measures to Achieve Social Mix and Their Impact to Access to Housing for People Who Are Homeless. European Journal of Homelessness, 1, 213-224.

Busch-Geertsema, V., \& Fitzpatrick, S. (2008). Effective Homelessness Prevention? Explaining Reductions in Homelessness in Germany and England. European Journal of Homelessness, 2, 69-95.

Busch-Geertsema, V., \& Sahlin, I. (2007) The Role of Hostels and Temporary Accommodation. European Journal of Homelessness, 1, 67-93.

Cloke, P., May, J., \& Johnsen, S. (2010). Swept Up Lives? Re-Envisioning the Homeless City. Oxford: Wiley-Blackwell. https://doi.org/10.1002/9781444324655

Connelly, J., \& Crown, J. (1994). Homelessness and Ill Health. London: Royal College of Physicians.

Culhane, D.P., \& Kuhn, R. (1998). Patterns and Determinants of Public Shelter Utilization among Homeless Adults in Philadelphia and New York City. Journal of Policy Analysis and Management, 17(1), 23-43. https://doi.org/10.1002/(SICI)1520-6688(199824)17:1\%3C23::AID-PAM2\%3E3.0.CO; 2-J

Edgar, B. (2009). European Review of Statistics on Homelessness. Brussels: FEANTSA 
Edgar, B. (2012). The ETHOS Definition and Classification of Homelessness and Housing Exclusion. European Journal of Homelessness, 6(2).

Edgar, B., \& Doherty, J. (eds.) (2001) Women and Homelessness in Europe. Pathways, Services and Experiences. Bristol: Policy Press.

FEANTSA (2006). The Right to Health Is a Human Right: Ensuring Access to Health for People Who Are Homeless: Annual European Report 2006 . Brussels: FEANTSA.

FEANTSA (2007). Multiple Barriers, Multiple Solutions: Inclusion into and through Employment for People Who Are Homeless: Annual Theme 2007 Employment and Homelessness (Brussels: FEANTSA).

FEANTSA (2010). Ending Homelessness: A Handbook for Policy Makers. Brussels: FEANTSA (European Federation of National Associations Working with the Homeless). Available

http://www.epha.org/IMG/pdf/HANDBOOK_TO_END_HOMELESSESS.pdf

Fitzpatrick, S. (1998). Homelessness in the European Union. In Kleinman, M., Matznetter, W., \& Stephens, M. (Eds.), European Integration and Housing Policy. London: Routledge and The Royal Institution of Chartered Surveyors.

Fitzpatrick, S. (2009). Homelessness in the UK in an international context, Chapter 10, pp.158-174. In Fitzpatrick, S., Quilgars, D., \& Pleace, N. (eds.), (2009) Homelessness in the UK: problems and solutions. Coventry: Chartered Institute of Housing.

Fitzpatrick, S., \& Stephens, M. (2007). An International Review of Homelessness and Social Housing Policy. London: Department for Communities and Local Government.

Frazer, H., Marlier, E., \& Nichaise, I. (2010). A Social Inclusion Roadmap for Europe 2020. Antwerpen/Apeldoorn: Garant.

Gassmann, F., Berulava, G., \& Tokmazashvili, M. (2013). Economic and Social Vulnerability. United Nations Development Programme in Georgia. ISBN 978-9941-0-5274-3

GEOSTAT (2011), Statistical Yearbook of Georgia 2011, National Statistics Office of Georgia, Tbilisi.

International Federation of Social Workers (IFSW) (2014). Statement in Support of Social Workers in South Caucasus Region. Available online at: http://ifsw.org/wp-content/uploads/2014/09/Statement-of-IFSW-Europe-in-Support-of-S ocial-Workers-in-South-Caucasus-Region.pdf (accessed 27 December 2014).

Marpsat, M. (2008). An Advantage with Limits. The Lower Risk for Women of Becoming Homeless. In: M. Marpsat (ed.), The INED Research on Homelessness, 1993-2008, Volume 1 (Paris: INED).

May, J. (2000). Housing Histories and Homelessness Carriers: A Bibliographical Approach. Housing Studies, 15(4), 613-638. https://doi.org/10.1080/02673030050081131 
McNaughton, C. (2008). Transitions through Homelessness: Lives on the Edge. Basingstoke: Palgrave Macmillan.

Meert, H.; Edgar, B., \& Doherty, J. (2004). 'Towards an Operational Definition of Homelessness and Housing Exclusion' Paper presented at the European Network of Housing Research Conference, 2nd - 6th July, 2004, Cambridge.

Ministry of Internally Displaced Persons from the Occupied Territories, Accommodation and Refugees of Georgia. http://www.mra.gov.ge/eng

National Strategy for the Protection of Human Rights in Georgia 2014-2020. http://gov.ge/index.php?lang_id=ENG\&sec_id=429\&info_id $=51454$

O'Flaherty, B. (2004). Wrong person and wrong place: for homelessness, the conjunction is what matters. Journal of Housing Economics, 13, 1-15. https://doi.org/10.1016/j.jhe.2003.12.001

Pleace, N. (2000). The New Consensus, the Old Consensus and the Provision of Services for People Sleeping Rough. Housing Studies, 15(4), 481-594. https://doi.org/10.1080/02673030050081113

Pleace, N. (2008). Effective Services for Substance Misuse and Homelessness in Scotland: Evidence from an International Review. Edinburgh: Scottish Government.

Pleace, N., \& Bretherton, J. (2013). Measuring Homelessness and Housing Exclusion in Northern Ireland: A test of the ETHOS typology. Belfast: Northern Ireland Housing Executive.

Public Defender of Georgia. (2015). Special Report on the Right to Adequate Housing. Georgia: Public Defender (Ombudsman) of Georgia.

Stephens, M., Fitzpatrick, S., Elsinga, M., van Steen, G., \& Chzhen, Y. (2010). Study on Housing Exclusion: Welfare Policies, Housing Provision and Labor Markets. Brussels: European Commission, Directorate-General for Employment, Social Affairs and Equal Opportunities.

Tarter, RE., \& Hegedu, A.M. (1991). The Drug Use Screening Inventory: Its applications in the evaluation of alcohol and other drug abuse. Alcohol Health and Research World, $15(1), 65-75$.

The office of the UN High Commissioner in Georgia (2011). The Right to Adequate Housing. Information brochure, 21(1), 31-32.

Tsemberis, S. (2010). Housing First: Ending Homelessness, Promoting Recovery and Reducing Costs. In: I. Gould Ellen and B. O'Flaherty (eds.), How to House the Homeless New York: Russell Sage Foundation.

United Nations. (2000). Enhancing social protection and reducing vulnerability in a globalizing world. Report of the Secretary-General to the Thirty-ninth Session E/CN. Washington DC: United Nations Economic and Social Council. 


\section{Macrothink}

Van Laere, I., De Wit, M. A., \& Klazinga, N. (2009). Pathways into Homelessness: Recently Homeless Adults' Problems and Servise Use Before and After Becoming Homeless in Amsterdam, BMC Public Health, 9(1), 3-11. https://doi.org/10.1186/1471-2458-9-3

Wright, N. M. J., \& Tompkins, C. N. E. (2005). How Can Health Care Systems Effectively Deal with the Major Health Care Needs of Homeless People? Copenhagen: World Health Organisation (Europe).

Note

Note 1 . This is almost $40 \%$ of all roofless people in Tbilisi, Georgia.

\section{Copyright Disclaimer}

Copyright for this article is retained by the author(s), with first publication rights granted to the journal.

This is an open-access article distributed under the terms and conditions of the Creative Commons Attribution license (http://creativecommons.org/licenses/by/3.0/). 